Pacific Journal of Mathematic 


\section{DETERMINANTS OF PETRIE MATRICES}

\section{MANFREd GoRdon aNd E. MaRTin Wilkinson}

The number of nonsingular square Petrie matrices is calculated by setting up a correspondence with spanning trees and then using Cayley's Theorem to count these trees. This work has applications in the 'excluded volume' problem in Polymer Science.

A Petrie matrix is a finite matrix whose elements are either zeros or ones such that the ones in each column occur consecutively. Such matrices have been studied in a molecular biological situation by Fulkerson and Gross [2] and in archaeology by Kendall [4 and 5] and Wilkinson [7]. The problem here treated has arisen from a combinatorial analysis [3] of the theory of the 'excluded volume' of a polymer chain [1], in which Petrie matrices play an important, though hitherto unrecognized, role.

The Fulkerson and Gross paper quotes the interesting fact that Petrie matrices are unimodular, that is all square sub-matrices have a determinant which is either $-1,0$, or 1 . The object of this paper is to investigate square Petrie matrices with the view of counting the number with nonzero determinant. We propose to do this by constructing a correspondence between $n$ by $n$ Petrie matrices and graphs on $n+1$ vertices with at most $n$ edges, and then to show that precisely those graphs that are spanning trees correspond to nonsingular Petrie matrices. A well known theorem by Cayley can then be used to count up the number of distinct labelled nonrooted trees.

$\begin{array}{llllll}1 & 0 & 0 & 1 & 0 & 0 \\ 1 & 1 & 0 & 0 & 1 & 0 \\ 1 & 1 & 1 & 0 & 1 & 1 \\ 0 & 1 & 1 & 0 & 1 & 1 \\ 0 & 1 & 0 & 0 & 1 & 1 \\ 0 & 1 & 0 & 0 & 0 & 0\end{array}$

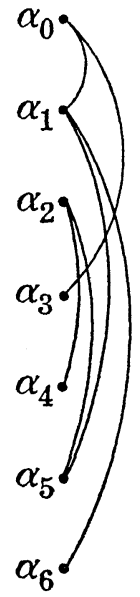


For an $n$ by $n$ Petrie matrix $A$, we construct a graph on $n+1$ points, which we label $\alpha_{0} \cdots \alpha_{n}$. If a column of $A$ has ones from row $i$ to row $j$ then we insert an edge between $\alpha_{i-1}$ and $\alpha_{j}$. Figure 1 illustrates the construction of a tree from a Petrie matrix.

If the graph has $m$ nonzero columns, there will be $m$ edges in the graph. So we have constructed a mapping from the set of $n$ by $n$ Petrie matrices to the graphs on $n+1$ points with at most $n$ edges. This mapping is onto, for given any such graph, we can trivially construct a Petrie matrix that maps onto it. If the graphs of two matrices are the same, then one is a column permutation of the other. So we can construct a one-to-one correspondence between the equivalence classes of Petrie matrices with respect to column permutations and the set of graphs.

THeOREM 1. A square Petrie matrix is nonsingular if and only if its associated graph is a spanning tree. The determinant is either 0,1 or -1 .

Proof. If the graph is not a spanning tree then either there is a circuit, or the graph is disconnected. If there is no circuit and the graph is disconnected then there are less than $n$ edges and hence at least one of the columns of $A$ must be all zeros. If there is a circuit then we can construct a linear dependence between the columns. Consider a journey round a circuit. When going from $\alpha_{i}$ to $\alpha_{j}$ along an edge, add the corresponding column of $A$ if $i>j$ and subtract if $j>i$. On completing the circuit the sum of these columns will be zero, since one has traversed each row as many times upwards as downwards.

If, on the other hand, the graph is a spanning tree, we prove by induction on $n$ that the determinant of the Petrie matrix is plus or minus one. If $n=1$ the result is true. Assume the hypothesis is true for all matrices of size $n-1$. There is at least one edge incident on $\alpha_{n}$. Consider those columns corresponding to edges incident on $\alpha_{n}$. There is just one ( $X$, say) with fewest ones, since otherwise there would be a circuit in the tree. We subtract this column $X$ from the others, leaving a new Petrie matrix with a single one in the last row. The determinant of the matrix is the cofactor of the single one in the last row. The graph corresponding to this determinant of order $(n-1)$ is obtained from that of the original determinant of order $n$ by elementary contraction of the edge corresponding to $X$, and thus is again a spanning tree.

TheOREM 2. There are $n !(n+1)^{n-1}$ distinct nonsingular $n$ by $n$ Petrie matrices. 
Proof. By Cayley's theorem, there are $(n+1)^{n-1}$ distinct vertexlabelled trees on $n+1$ vertices. Each tree corresponds to a class of Petrie matrices. The columns are necessarily distinct and so each class contains $n$ ! distinct matrices.

It is clear that there are $((n(n+1)) / 2+1)^{n}$ distinct Petrie matrices, so the proportion that are nonsingular tends to zero as $n$ tends to infinity. This is interesting because for the general class of $n$ by $n$ $(0,1)$-matrices, of which Petrie matrices form a sub-class, Komlós [6] has proved the opposite kind of asymptotic behavior: for them, the fraction of nonsingular ones tends to unity.

Acknowledgement. M. Gordon wishes to thank Professors D. G. Kendall and P. Whittle for hospitality at the Statistical Laboratory and Corpus Christi College for a Visiting Scholarship. E. M. Wilkinson wishes to thank the S.R.C. for a Research Studentship.

\section{REFERENCES}

1. M. Fixman, Excluded volume in polymer chains, J. Chem. Phys., 23 (1955), 1656.

2. D. R. Fulkerson and O, A. Gross, Incidence matrices and interval graphs, Pacific J. Math., 15, 3, (1965), 835-855.

3. M. Gordon, S. B. Ross-Murphy, and H. Suzuki, to be published.

4. D. G. Kendall, Incidence matrices, interval graphs, and seriation in archaeology, Pacific. J. Math., 28, 3, (1969), 565-570.

5. - Seriation from Abundance Matrices, Mathematics in the Archaeological and Historical Sciences, Edinburgh University Press, (1971), 215-252.

6. J. Komlós, On the determinant of $(0,1)$ matrices, Studia Sci. Math. Hung., 2 (1967), 7.

7. E. M. Wilkinson, Archaeological Seriation and the Travelling Salesman Problem, Mathematics in the Archaeological and Historical Sciences, Edinburgh University Press, (1971), 276-287.

Received October 4, 1972.

UNIVERSITY OF CAMBRIDGE

Permanent address: Chemistry Department, University of Essex, Colchester, England AND

Present address: Van den Berghs \& Jurgens Ltd., Cheshire L62 3NU, England 



\section{PACIFIC JOURNAL OF MATHEMATICS}

\section{EDITORS}

RICHARD ARENS (Managing Editor)

University of California

Los Angeles, California 90024
J. DUGUNDJI*

Department of Mathematics

University of Southern California

Los Angeles, California 90007

D. Gilbarg and J. Milgram

Stanford University

Stanford, California 94305
University of Washington

Seattle, Washington 98105

ASSOCIATE EDITORS
E. F. BECKENBACH
B. H. NeumanN
F. WoLF
K. YosHIDA

\section{SUPPORTING INSTITUTIONS}

\author{
UNIVERSITY OF BRITISH COLUMBIA \\ CALIFORNIA INSTITUTE OF TECHNOLOGY \\ UNIVERSITY OF CALIFORNIA \\ MONTANA STATE UNIVERSITY \\ UNIVERSITY OF NEVADA \\ NEW MEXICO STATE UNIVERSITY \\ OREGON STATE UNIVERSITY \\ UNIVERSITY OF OREGON \\ OSAKA UNIVERSITY
}

\author{
UNIVERSITY OF SOUTHERN CALIFORNIA \\ STANFORD UNIVERSITY \\ UNIVERSITY OF TOKYO \\ UNIVERSITY OF UTAH \\ WASHINGTON STATE UNIVERSITY \\ UNIVERSITY OF WASHINGTON
* * * *
AMERICAN MATHEMATICAL SOCIETY \\ NAVAL WEAPONS CENTER
}

The Supporting Institutions listed above contribute to the cost of publication of this Journal, but they are not owners or publishers and have no responsibility for its content or policies.

Mathematical papers intended for publication in the Pacific Journal of Mathematics should be in typed form or offset-reproduced, (not dittoed), double spaced with large margins. Underline Greek letters in red, German in green, and script in blue. The first paragraph or two must be capable of being used separately as a synopsis of the entire paper. Items of the bibliography should not be cited there unless absolutely necessary, in which case they must be identified by author and Journal, rather than by item number. Manuscripts, in duplicate if possible, may be sent to any one of the four editors. Please classify according to the scheme of Math. Rev. Index to Vol. 39. All other communications to the editors should be addressed to the managing editor, or Elaine Barth, University of California, Los Angeles, California, 90024.

100 reprints are provided free for each article, only if page charges have been substantially paid. Additional copies may be obtained at cost in multiples of 50 .

The Pacific of Journal Mathematics is issued monthly as of January 1966. Regular subscription rate: $\$ 72.00$ a year (6 Vols., 12 issues). Special rate: $\$ 36.00$ a year to individual members of supporting institutions.

Subscriptions, orders for back numbers, and changes of address should be sent to Pacific Journal of Mathematics, 103 Highland Boulevard, Berkeley, California, 94708.

PUBLISHED BY PACIFIC JOURNAL OF MATHEMATICS, A NON-PROFIT CORPORATION

Printed at Kokusai Bunken Insatsusha (International Academic Printing Co., Ltd.), 270, 3-chome Totsuka-cho, Shinjuku-ku, Tokyo 160, Japan.

* C. R. DePrima California Institute of Technology, Pasadena, CA 91109, will replace J. Dugundji until August 1974.

Copyright (C) 1973 by Pacific Journal of Mathematics

Manufactured and first issued in Japan 


\section{Pacific Journal of Mathematics}

\section{Vol. 51, No. $2 \quad$ December, 1974}

Robert F. V. Anderson, Laplace transform methods in multivariate spectral theory .................................................. 339

William George Bade, Two properties of the Sorgenfrey plane . . . . . . . . . . . . 349

John Robert Baxter and Rafael Van Severen Chacon, Functionals on continuous

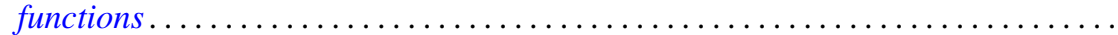

Phillip Wayne Bean, Helly and Radon-type theorems in interval convexity

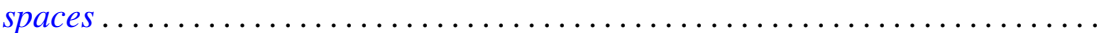

James Robert Boone, On k-quotient mappings $\ldots \ldots \ldots \ldots \ldots \ldots \ldots \ldots \ldots$

Ronald P. Brown, Extended prime spots and quadratic forms . . . . . . . . . . . .

William Hugh Cornish, Crawley's completion of a conditionally upper continuous lattice .............................................

Robert S. Cunningham, On finite left localizations ...................

Robert Jay Daverman, Approximating polyhedra in codimension one spheres

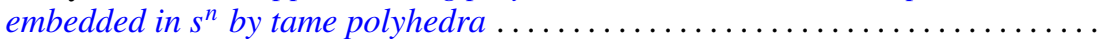

Burton I. Fein, Minimal splitting fields for group representations . . . . . . . . . . . .

Peter Fletcher and Robert Allen McCoy, Conditions under which a connected

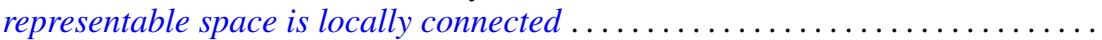

Jonathan Samuel Golan, Topologies on the torsion-theoretic spectrum of a noncommutative ring...

Manfred Gordon and Edward Martin Wilkinson, Determinants of Petrie matrices.

Alfred Peter Hallstrom, A counterexample to a conjecture on an integral condition for determining peak points (counterexample concerning peak points)........

E. R. Heal and Michael Windham, Finitely generated $F$-algebras with applications to Stein manifolds.

Denton Elwood Hewgill, On the eigenvalues of a second order elliptic operator in an unbounded domain ............................

Charles Royal Johnson, The Hadamard product of $A$ and $A^{*}$.

Darrell Conley Kent and Gary Douglas Richardson, Regular completions of Cauchy spaces.

Alan Greenwell Law and Ann L. McKerracher, Sharpened polynomial approximation

Bruce Stephen Lund, Subalgebras of finite codimension in the algebra of analytic functions on a Riemann surface. .

Robert Wilmer Miller, TTF classes and quasi-generators . .

Roberta Mura and Akbar H. Rhemtulla, Solvable groups in which every maximal partial order is isolated ....

Isaac Namioka, Separate continuity and joint continuity...

Alan Saleski, Entropy of self-homeomorphisms of statistical pseudo-metric

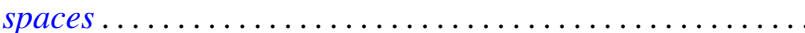

H. A. Seid, Cyclic multiplication operators on $L_{p}$-spaces .....

H. B. Skerry, On matrix maps of entire sequences ............

John Brendan Sullivan, A proof of the finite generation of invariants of a normal

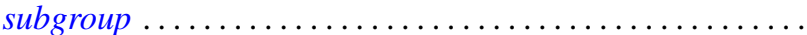

John Griggs Thompson, Nonsolvable finite groups all of whose local subgroups are

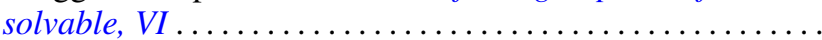

